\title{
Communication \\ Culicoides insignis Lutz, 1913 (Diptera: Ceratopogonidae) Biting Midges in Northeast of Brazil
}

\author{
Raisa Rodrigues Santos Rios ${ }^{1}$, Maria Clara Alves Santarém ${ }^{2}$, Karlos Antônio Lisboa Ribeiro Júnior ${ }^{3}$, \\ Breno Araujo de Melo ${ }^{1}$, Sybelle Georgia Mesquita da Silva ${ }^{1}$, Neuriane Cavalcante da Silva ${ }^{3}$, \\ Vitória Regina Viana dos Santos ${ }^{3}$, Jakeline Maria dos Santos ${ }^{3}$, Antônio Euzébio Goulart Santana ${ }^{3}$ \\ and Angelina Bossi Fraga $3, *$ (i)
}

Citation: Rios, R.R.S.; Santarém, M.C.A.; Ribeiro Júnior, K.A.L.; de Melo, B.A.; da Silva, S.G.M.; da Silva, N.C.; dos Santos, V.R.V.; dos Santos, J.M.; Santana, A.E.G.; Fraga, A.B. Culicoides insignis Lutz, 1913 (Diptera: Ceratopogonidae) Biting Midges in Northeast of Brazil. Insects 2021, 12, 366. https://doi.org/10.3390/ insects12040366

Academic Editor: Andre Barreto Bruno Wilke

Received: 16 March 2021

Accepted: 17 April 2021

Published: 20 April 2021

Publisher's Note: MDPI stays neutral with regard to jurisdictional claims in published maps and institutional affiliations.

Copyright: (c) 2021 by the authors. Licensee MDPI, Basel, Switzerland. This article is an open access article distributed under the terms and conditions of the Creative Commons Attribution (CC BY) license (https:/ / creativecommons.org/licenses/by/ $4.0 /)$.
1 Northeast Network of Biotechnology—RENORBIO, Federal University of Alagoas, Av. Lourival Melo Mota S/N, Tabuleiro dos Martins, 57072-900 Maceió, Brazil; raisa.rios@hotmail.com (R.R.S.R.); breno_melo13@hotmail.com (B.A.d.M.); belle_mesquita21@hotmail.com (S.G.M.d.S.)

2 Ceratopogonidae Collection, Oswaldo Cruz Foundation (FIOCRUZ), Av. Brasil, Manguinhos, 4365 Rio de Janeiro, Brazil; mariaclarasantarem@gmail.com

3 Campus of Engineering and Agrarian Science-CECA, Federal University of Alagoas, BR-104, 57100-000 Rio Largo, Brazil; karloslisboa@gmail.com (K.A.L.R.J.); neurianecavalcante@gmail.com (N.C.d.S.); vihfirmino@gmail.com (V.R.V.d.S.); jackbilu@hotmail.com (J.M.d.S.); aegsal@gmail.com (A.E.G.S.)

* Correspondence: angelina.fraga@gmail.com; Tel.: +55-82-99341-3092

Simple Summary: Culicoides genus insects are spread throughout the world, and some species are vectors of important human and animal diseases. Genetic identification, as well as the local occurrence of these insects, are fundamental to the development of risk profiles and entomological surveillance of transmitted diseases. We investigated the Culicoides occurrence in Alagoas State, northeastern Brazil. Midges were captured with light traps, being morphologic and genetic identified. After PCR analysis and GenBank database comparison, it was confirmed that the captured midges belong to Culicoides insignis. This was the first formal report of Culicoides insignis occurrence in Alagoas State, northeastern Brazil.

Abstract: The species of the Culicoides genus are hematophagous, and some of them are vectors of important human and animal diseases. This group of insects is distributed worldwide, varying according to local species. Knowledge of the geographic distribution of specific species is crucial for the development and implementation of control strategies. The aim of this work was to investigate the occurrence of Culicoides in the state of Alagoas in northeast Brazil. Midges were captured with CDC light traps, and their identification and morphological analyses were performed by the Ceratopogonidae Collection of the Oswaldo Cruz Foundation (FIOCRUZ/CCER) in Rio de Janeiro, Brazil. Morphological analyses were performed using the key to Culicoides from the guttatus group and comparison with other deposited specimens. DNA sequencing, genetic analysis and comparison with sequences in the Genbank database, confirmed the identification of the flies as Culicoides insignis. This was the first formal report of $C$. insignis being found in Alagoas.

Keywords: Culicoides; hematophagous insects; light traps

\section{Introduction}

Members of the genus Culicoides Latreille, 1809 are Diptera of the family Ceratopogonidae. Also known as biting midges or no-see-ums, these are among the most important and the smallest members of this family, measuring approximately 1.5 to $5 \mathrm{~mm}$ in length. Their wings have a pattern of dark and pale spots, which aid in species identification. They are one of the most important hematophagous insects in this family and females of some Culicoides species can transmit, through their bites, the causative agents of important 
veterinary diseases, including Bluetongue [1] Schmallenberg [2] African horse sickness [3] epizootic hemorrhagic disease (EHD), equine encephalosis (EE), Akabane (AKA), and bovine ephemeral fever (BEF) [4]. The main symptoms of these diseases include edema, fever, and ulceration [5]. Additionally, Culicoides paraensis (Goeldi) is recognized as the vector of the Oropouche virus, which infects humans primarily in the Brazilian Amazon Region [6].

These insects are widely distributed across the globe, being reported in diverse environments and up to $4000 \mathrm{~m}$ of altitude [4]. The impact of these insects on public health, as important disease vectors, was highlighted by the use of models to predict the presence and abundance of C. imicola, the most important vector of BTV, in both Europe and Africa [7]. A modeling work conducted in Argentina evaluated the occurrence and distribution of C. insignis, in order to develop risk profiles for BTV [8].

In Brazil, 299 species of Culicoides were reported, most of them in the Amazon Region. In Northeast Brazil, no Ceratopogonidae species have ever been reported in the states of Alagoas and Sergipe [9]. The identification of the species of vectors plays an important role in determining the epidemiology and pathogens transmission. Small differences in the biology and ecology of systematically closely related species may have large effects on the probability of transmission of disease. Therefore, the accurate identification of species is basic to understanding the epidemiology of disease transmission [10]. This work aimed to investigate the occurrence of the Culicoides in the state of Alagoas, in northeast Brazil.

\section{Materials and Methods}

\subsection{Morphological Identification}

Insects were collected between June 2019 and September 2019 in the rainy season at Satuba city, Alagoas State, northeastern Brazil (09 $33^{\prime} 46^{\prime \prime}$ E; $35^{\circ} 49^{\prime} 26^{\prime \prime}$ W). Midges were captured with CDC (Center on Disease Control) light traps, powered by electricity, that were put five days per week at the sheepfolds in twilight (5 pm) and picked up in the morning $(7 \mathrm{am})$ the next day. After that, the insects were preserved in $70 \%$ ethanol solution, taken to the laboratory, and rinsed in distilled water. The specimens were slide mounted as described [11] except for fixation in Hoyer solution. The slide-mounted species were photomicrographed using a NIKON Eclipse E-200 microscope. Morphological identification was performed by the Fiocruz Ceratopogonidae Collection, Rio de Janeiro, Brazil, using the key to Culicoides from the guttatus group [12] and comparison with other deposited specimens.

\subsection{DNA Extraction, COI (Cytochrome Oxidase I) Gene Amplification and Gene Submission to GenBank}

Total nucleic acids were extracted following a modified Chelex method. Culicoides spp adults were crushed and homogenized in $20 \mu \mathrm{L}$ of $6 \%$ Chelex solution in a $0.2 \mathrm{~mL}$ Eppendorf tube. The tube was agitated for a few seconds and then incubated at $57^{\circ} \mathrm{C}$ for $15 \mathrm{~min}$ and at $99^{\circ} \mathrm{C}$ for $3 \mathrm{~min}$. After centrifugation at 13,000 rpm for $5 \mathrm{~min}$, the supernatant was collected and used as a template for PCR amplification [13].

The PCRs were performed on a T100 thermal cycler (BioRad, Foster City, CA, USA) adjusted to the following thermal conditions: DNA denaturation and polymerase activation at $94{ }^{\circ} \mathrm{C}$ for $2 \mathrm{~min}$, followed by 30 cycles at $95^{\circ} \mathrm{C}$ for $30 \mathrm{~s}$ (denaturation), $48{ }^{\circ} \mathrm{C}$ for $45 \mathrm{~s}$ (annealing), and $72{ }^{\circ} \mathrm{C}$ for $45 \mathrm{~s}$ (extension), and $72{ }^{\circ} \mathrm{C}$ for $10 \mathrm{~min}$ (final elongation). The PCR products were subjected to electrophoresis on a $1.0 \%$ agarose gel and stained with SYBR $^{\circledR}$ Gold for visualization [14]. PCR products amplified from mtCOI of Culicoides spp were purified using a QIAquick Gel Extraction Kit (Qiagen Inc, Valencia, CA, USA) and sequenced using a Macrogen instrument (Macrogen Inc, Seoul, South Korea) in both directions using the forward primer (LCO1490) 5'-GGTCAACAAATCATAAAGATATTGG-3' and reverse primer (HCO2198) 5'-TAAACTTCAGGGTGACCAAAAAATCA-3' [15].

Sequenced data were checked for quality by Codon Code Aligner v. 6.0.2 (www. codoncode.com) (Codon Code Corporation, Dedham, MA, USA). Homology, insertions- 
deletions, stop codons, and frameshifts were checked using NCBI BLAST. BankIt, a WWWbased submission tool with wizards to guide the submission process, was used. The GenBank database is intended for new sequence data that were determined and annotated by the submitter. All sequences were uploaded to GenBank.

\subsection{Data Analysis}

The determined sequences were manually edited with Codon Code ${ }^{\circledR}$ (version 6.0.2) to produce a consensus sequence of $\sim 670 \mathrm{bp}$. The sequences were aligned using the multiple sequence comparison by log expectation (MUSCLE) program in Mega, version 10.1.7 [16]. The sequences were compared with publicly available sequences in the Barcode of Life Data System (BOLD) database to establish their relationship [17].

\section{Results and Discussion}

\subsection{Morphological Identification}

A total of 741 specimens (518 males and 223 females) were collected, and all of them belonged to only one species, identified by the Fiocruz Ceratopogonidae Collection as C. insignis Lutz, 1913 (Figure 1). This was the first formal record of Ceratopogonidae in Alagoas, Brazil. Since the Culicoides genus has been reported in almost all Brazilian states, except in the states of Alagoas, Tocantins, Rio Grande Norte, Sergipe and Distrito Federal [9]. Additionally, little is known about the Culicoides fauna in Caatinga, an important and biodiverse Brazilian biome.

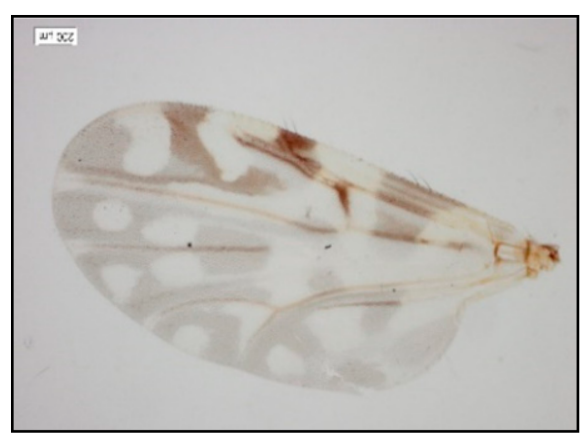

(A)

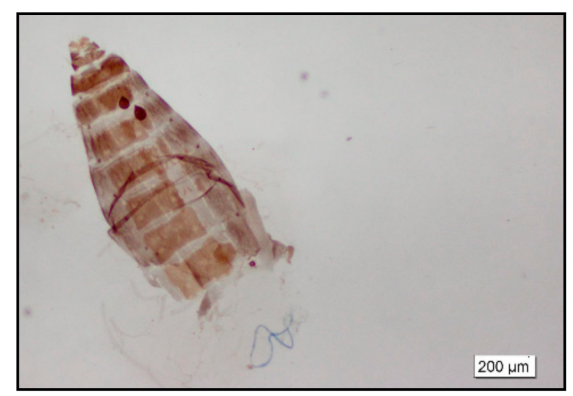

(C)

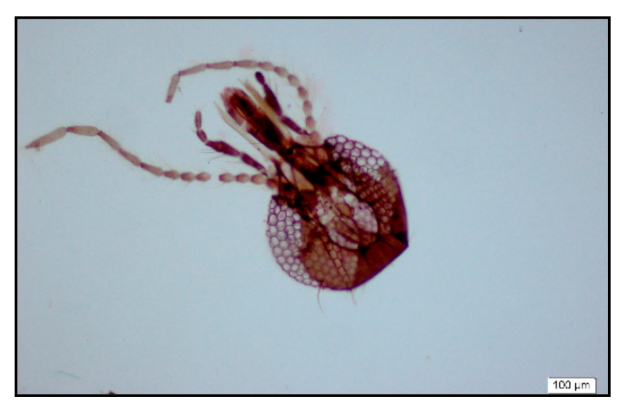

(B)

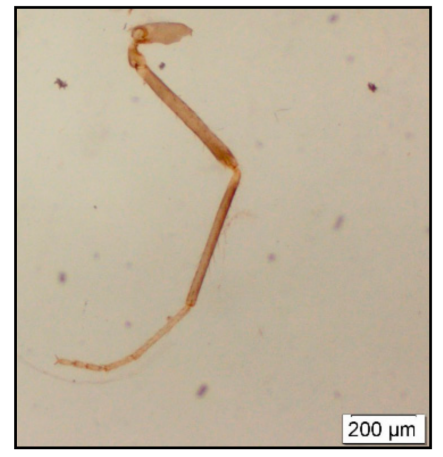

(D)

Figure 1. Body parts of Culicoides insignis Lutz, 1913: female, (A) wings; (B) head, anterior view; (C) abdomen, ventral view; (D) midleg.

The occurrence of this species in a large number of farm environments near sheep farming is an important epidemiological record. Culicoides insignis is the main vector of Bluetongue virus (BTV) in the Neotropical Region to domestic and wild ruminants in the Neotropical region [18]. This species is essentially zoophilic and is often associated with cattle [19]. It is also found in manure and wet pasture areas, as well as mangroves, stream banks and sugar cane plantations [20]. This behavior highlights its importance as vectors 
of this disease to these animals, as well as in allergic dermatitis caused by their bite. Its distribution occurs throughout the Neotropical Region up to the south of Florida, with a peak population in rainy and hot seasons, which may constitute almost the totality of species captured in this period in areas with available hosts. Culicoides insignis has been shown to be a competent vector of serotypes BTV 2 and 11 in Neotropical areas [21]. This fact suggests that $C$. insignis may act as a vehicle for the expansion of serotypes from the Caribbean, Central America and south Florida and further north and for the expansion of serotypes from the northern USA to the south [22].

\subsection{Molecular Identification}

To determine the relationship of the identified species within the genus Culicoides, maximum likelihood analysis of the 645-bp COI sequences (after removing the $5^{\prime}$ - and $3^{\prime}$-end regions) was conducted using the 30 sequences identified in this study and the most identical sequences of corresponding Culicoides species obtained from the BOLD database (Table 1). According to the subgeneric classification of [23] the species identified in this study were classified into the Ceratopogoninae subfamily, Culicoidini tribe and Culicoides genus.

Table 1. Sequence ID of 30 COI sequences of collected Culicoides midges in various regions of America and their identity searched in the BOLD system database.

\begin{tabular}{cccc}
\hline Species & Sequence ID & Collection Site & Country \\
\hline Culicoides sonorensis & BBDIT1920-12 & Texas & United States \\
Culicoides sonorensis & BBDIV1423-12 & California & United States \\
Culicoides sonorensis & BBDIV281-12 & California & United States \\
Culicoides sonorensis & BBDIV461-12 & California & United States \\
Culicoides sonorensis & BBDIV647-12 & New mexico & United States \\
Culicoides sonorensis & CNGRD391-12 & Saskatchewan & Canada \\
Culicoides sonorensis & CNGSB2323-12 & Saskatchewan & Canada \\
Culicoides haematopotus & GBMNA39319-19 & Texas & United States \\
Culicoides haematopotus & GBMNA39320-19 & Texas & United States \\
Culicoides haematopotus & GBMNA39321-19 & Texas & United States \\
Culicoides haematopotus & GBMNA39322-19 & Texas & United States \\
Culicoides haematopotus & GBMNA39323-19 & Texas & United States \\
Culicoides haematopotus & GBMNA39330-19 & Texas & United States \\
Culicoides haematopotus & GBMNA39332-19 & Texas & United States \\
Culicoides stellifer & GBMNB14874-20 & Texas & United States \\
Culicoides stellifer & GBMNB14875-20 & Texas & United States \\
Culicoides stellifer & BARSD143-16 & Ontario & Canada \\
Culicoides stellifer & BARSE114-16 & Ontario & Canada \\
Culicoides stellifer & GBMNB14876-20 & Texas & United States \\
Culicoides stellifer & GBMNB14877-20 & Texas & United States \\
Culicoides stellifer & GBMNB14878-20 & Texas & United States \\
Culicoides stellifer & GBMNB14879-20 & Texas & United States \\
\hline
\end{tabular}

The sequences obtained in the present study have been deposited in GenBank under the accession numbers C. insignis MT806183 and MW871560-MW871562. All the species from north America showed in Table 2 were at least 79\% identical to specimens reported here. The genetic distance pairwise between C. insignis from Brazil and C. sonorensis, C. haematopotus, and C. stellifer, were $82.80 \%, 82.10 \%$ and $80.00 \%$, respectively (Table 2). Highlighting, the estimations between the genetic distance pairwise from Culicoides midges from America, as showed in Table 2, have similar genetic homology to our finds. For example, C. sonorensis was $84.00 \%$ identical to $C$. stellifer. A recent paper discussed the expansion of the range of C. insignis in Florida and the southeastern U.S. [24]. Although C. insignis is more widespread in Brazil, this is considered yet another example of the expansion of its range. 
Table 2. Estimation of pairwise distances between sampled species for COI of the mtDNA.

\begin{tabular}{lcccccc}
\hline & $\mathbf{1}$ & $\mathbf{2}$ & $\mathbf{3}$ & $\mathbf{4}$ & $\mathbf{5}$ & $\mathbf{6}$ \\
\hline 1. C. insignis (MT806183) & & & & & & \\
2. C. sonorensis (BBDIV1423) & 0.172 & & & & & \\
3. C. sonorensis (BBDIV461) & 0.174 & 0.004 & & & & \\
4. C. haematopotus (GBMNA39330) & 0.179 & 0.212 & 0.217 & & & \\
5. C. haematopotus (GBMNA39332) & 0.182 & 0.209 & 0.213 & 0.012 & & \\
6. C. stellifer (GBMNB14874) & 0.200 & 0.170 & 0.157 & 0.220 & 0.224 & \\
7. C. stellifer (GBMNB14876) & 0.200 & 0.174 & 0.157 & 0.220 & 0.224 & 0.182 \\
\hline
\end{tabular}

This is the first sequence of the COI gene from Culicoides insignis, and it is the first DNA fragment sequence from an important widespread Brazilian species. These data can collaborate with studies on Culicoides genetic diversity in Brazil and provide support for epidemiological studies on Bluetongue virus transmission.

\section{Conclusions}

This is the first report of a member of the Ceratopogonidae, Culicoides insignis, in Alagoas, Brazil, and first report of the COI gene sequence for this species in Brazil.

Author Contributions: Conceptualization, A.B.F. and A.E.G.S.; methodology, R.R.S.R., J.M.d.S., M.C.A.S., K.A.L.R.J.; software, K.A.L.R.J.; validation, R.R.S.R., J.M.d.S., M.C.A.S. and K.A.L.R.J.; formal analysis, M.C.A.S. and K.A.L.R.J.; investigation, R.R.S.R., A.B.F., B.A.d.M. and S.G.M.d.S.; resources, A.B.F. and A.E.G.S.; data curation, R.R.S.R., N.C.d.S. and V.R.V.d.S.; writing-original draft preparation, R.R.S.R.; writing—review and editing, A.B.F. and A.E.G.S.; visualization, A.E.G.S.; supervision, A.B.F.; project administration, A.B.F.; funding acquisition, A.B.F. All authors have read and agreed to the published version of the manuscript.

Funding: This research was funded by Research Support Foundation from the State of AlagoasFAPEAL and Coordination of Improvement of Higher-Level Personnel-CAPES, grant number 001.

Institutional Review Board Statement: The study was conducted according to the guidelines of the Declaration of Helsinki, and approved by Ethics Committee of Federal University of Alagoas (protocol code 52/2017 and date of approval: 09/06/2017).

Data Availability Statement: The data generated during the study have already been reported in the manuscript.

Conflicts of Interest: The authors declare no conflict of interest.

\section{References}

1. Du Toit, M. The Transmission of Bluetongue and Horse Sicknes by Culicoides. J. Vet. Sci. Anim. Ind. 1944, 19, 7-10.

2. Hoffmann, B.; Scheuch, M.; Höper, D.; Jungblut, R.; Holsteg, M.; Schirrmeier, H.; Eschbaumer, M.; Goller, K.V.; Wernike, K.; Fischer, M.; et al. Novel orthobunyavirus in Cattle, Europe 2011. Emerg. Infect. Dis. 2012, 18, 469-472. [CrossRef]

3. Henning, M.W. African Horse Sickness, Perdesiekte, Pestis Equorum. Animal Diseases of South. Africa, 3rd ed.; Central News Agency Ltd.: Pretoria, South Africa, 1956; pp. 785-808.

4. Mellor, P.S.; Boorman, J.; Baylis, M. Culicoides biting midges: Their role as arbovirus vectors. Annu. Rev. Entomol. 2000, 45, 307-340. [CrossRef]

5. Sperlova, A.; Zendulkova, D. Bluetongue: A review. Vet. Med. 2011, 56, 430-452. [CrossRef]

6. Wirth, W.; Felippe-Bauer, M.L. The neotropical biting midges related to Culicoides paraensis (Diptera: Ceratopogonidae). Mem. Inst. Oswaldo Cruz. 1989, 84, 551-565. [CrossRef]

7. Tatem, A.J.; Baylis, M.; Mellor, P.S.; Purse, B.V.; Capela, R.; Pena, I.; Rogers, D.J. Prediction of bluetongue vector distribution in Europe and north Africa using satellite imagery. Vet. Microbiol. 2003, 97, 13-29. [CrossRef]

8. Veggiani Aybar, C.A.; Gómez, R.D.; Dantur Juri, J.M.; Grosso, S.M.; Spinelli, G.R. Potential Distribution Map of Culicoides insignis (Diptera: Ceratopogonidae), Vector of Bluetongue Virus, in Northwestern Argentina. J. Insect. Sci. 2016, 16, 1-7. [CrossRef]

9. Brazilian Species of Biting Midges. Available online: https://portal.fiocruz.br/sites/portal.fiocruz.br/files/documentos/ brazilian_species_of_biting_midges_2020_0.pdf (accessed on 7 September 2020).

10. Harrup, L.E.; Bellis, G.A.; Balenghien, T.; Garros, C. Culicoides Latreille (Diptera: Ceratopogonidae) taxonomy: Current challenges and future directions. Infect. Genet. Evol. 2015, 30, 249-266. [CrossRef] 
11. Wirth, W.W.; Marston, N. A Method for Mounting Small Insects on Microscope Slides in Canada Balsam. Ann. Entomol. Soc. Am. 1968, 61, 783-784. [CrossRef]

12. Spinelli, G.R.; Greiner, E.C.; Wirth, W.W. The neotropical bloodsucking midges of the Culicoides guttatus group of the subgenus Hoffmania (Diptera: Ceratopogonidae). Contr. Am. Entomol. Inst. 1993, 27, 1-91.

13. De Moraes, L.A.; Marubayashi, J.M.; Yuki, V.A.; Ghanim, M.; Bello, V.H.; De Marchi, B.R.; Barbosa, L.F.; Boykin, L.M.; KrauseSakate, R.; Pavan, M.A. New invasion of Bemisia tabaci Mediterranean species in Brazil associated to ornamental plants. Phytoparasitica 2017, 45, 517-525. [CrossRef]

14. Tuma, R.S.; Beaudet, M.P.; Jin, X.; Jones, L.J.; Cheung, C.Y.; Yue, S.; Singer, V.L. Characterization of SYBR Gold Nucleic Acid Gel Stain: A Dye Optimized for Use With 300-nm Ultraviolet Transilluminators. Anal. Biochem. 1999, 268, 278-288. [CrossRef]

15. Folmer, O.; Black, M.; Hoeh, W.; Lutz, R.; Vrijenhoek, R. DNA primers for amplification of mitochondrial cytochrome c oxidase subunit I from diverse metazoan invertebrates. Mol. Mar. Biol. Biotech. 1994, 3, 294-299.

16. Kumar, S.; Stecher, G.; Li, M.; Knyaz, C.; Tamura, K. Mega x: Molecular evolutionary genetics analysis across computing platforms. Mol. Biol. Evol. 2018, 35, 1547-1549. [CrossRef]

17. Ratnasingham, S.; Hebert, P.D.N. BOLD: The Barcode of Life Data System (www.barcodinglife.org). Mol. Ecol. Notes 2007, 7, 355-364. [CrossRef]

18. Ronderos, M.M.; Greco, N.M.; Spinelli, G.R. Diversity of biting midges of the genus Culicoides Latreille (Diptera: Ceratopogonidae) in the area of the Yacyretá Dam Lake between Argentina and Paraguay. Mem. Inst. Oswaldo Cruz 2003, 98, 19-24. [CrossRef]

19. Davies, J.F. The distribution of sandfiies (Culicoides spp.) breeding in a tidal mangrove swamp in Jamaica and the effect of tides on the emergence of C. furens (Poey) and C. barbosai (Wirth \& Blanton). West Indian Med. J. 1967, 41, 39-50.

20. Wirth, W.W.; Blanton, F.S. A review of the maruins or biting midges of the genus Culicoides (Diptera: Ceratopogonidae) in the Amazon Basin. Amazoniana 1973, 4, 405-470.

21. Tanya, V.N.; Greiner, E.C.; Gibbs, E.P.J. Evaluation of Culicoides insignis (Diptera: Ceratopogonidae) as a vector of bluetongue virus. Vet. Microbiol. 1992, 32, 1-14. [CrossRef]

22. Homan, E.J.; Mo, C.L.; Thompson, L.H.; Barreto, C.H.; Oviedo, M.T.; Gibbs, E.P.; Greiner, E.C. Epidemiologic study of bluetongue viruses in Central America and the Caribbean: 1986-1988. Regional Bluetongue Team. Am. J. Vet. Res. 1990, 51, 1089-1094.

23. World Species of Biting Midges (Diptera: Ceratopogonidae). Available online: https://www.inhs.illinois.edu/files/4514/6410/ 0252/CeratopogonidaeCatalog.pdf (accessed on 16 March 2021).

24. Vigil, S.L.; Rudner, M.G.; Shaw, D.; Wlodkowski, J.; Garrett, K.; Walter, M.; Corn, J.L. Apparent range expansion of Culicoides (Hoffmania) insignis (Diptera: Ceratopogonidae) in the southeastern United States. J. Med. Entomol. 2018, 55, 1043-1046. [CrossRef] 